\title{
Primary and secondary prevention of uterine cervical cancer: Up-To-Date Information, Guidelines, and the need for their application in Greece
}

\author{
Dimitra Mitsopoulou*, Angeliki-Astero Papathanasiou*, Emmanouil Kalampokas, \\ Nikolaos Vlahos
}

Second Department of Obstetrics and Gynecology, National and Kapodistrian University of Athens, Medical School, Aretaieion Hospital, Vasilissis Sofias Avenue 76, Athens 115 28, Athens, Greece

*These authors contributed equally to the manuscript as first author

\section{Corresponding Author}

Dimitra Mitsopoulou, Second Department of Obstetrics and Gynecology, National and Kapodistrian University of Athens, Medical, e-mail: dimits96@gmail.com

\section{Abstract}

Background/Aim: Human papilloma virus (HPV) and uterine cervical cancer (UCC) are causatively related. In Greece, evidence-based guidelines for primary and secondary prevention of UCC have yet to be developed and applied in clinical practice. Our purpose here is to present such guidelines together with up-to-date data on HPV screening protocols.

Methods: We surveyed current literature on UCC prevention, national and international data on UCC, and national guidelines on UCC preventive measures in various countries, as well as their role in UCC control.

Results: It is well known that clinical practice guidelines optimize patient care. Introduction of guidelines regarding primary and secondary prevention of UCC express a favorable outcome of control and elimination of the disease. This is outlined in screening protocols of several countries worldwide. The lack of such guidelines in Greece in previous years led to misinformation of both healthcare professionals and general population. The development of clear and up-to-date guidelines in Greece during 2021 constitutes an important step that will play a pivotal role in UCC prevention in Greece. What needs to be ensured is on the one hand that all healthcare professionals are informed about these guidelines and on the other hand the application of these guidelines an everyday clinical practice.

Conclusions: Systematic use of primary and secondary preventive measures and screening protocols are efficient in both control and elimination of UCC. Based on our search and our clinical experience, it is imperative for all Obstetrics and Gynecology clinicians in Greece to be familiar with all relevant screening and vaccination programs available.

Key words: HPV, Vaccination, screening, guidelines 


\section{Introduction}

Uterine cervical cancer (UCC) is the fourth most common type of cancer in females, with an annual incidence of 570,000 cases worldwide and 696 cases in Greece. Globally, around 311,000 deaths are reported due to UCC, while in Greece, it is the third most common cause of cancer-related death in women aged between 15 and $44^{1}$. Human papilloma virus (HPV), which is the most common sexually transmitted infection, has been shown to be related to UCC. There are more than 200 types of HPV. High-risk HPV types are associated with uterine cervical, vulvar, vaginal, penile, anal, and head and neck cancers ${ }^{2}$. It is reported that $70 \%$ of precancerous and cancerous lesions of the uterine cervix are related to HPV types 16 and $18^{3}$. Observed declines in UCC incidence and morbidity are related to primary and secondary preventive measures, such as HPV vaccination, Papanicolaou (Pap) testing, and HPV DNA testing. Our aim in this paper is to highlight that primary and secondary preventative measures constitute the cornerstone of a complete and effective approach to UCC control, and can even enable the total elimination of UCC.

\section{Primary Prevention}

\section{Human Papilloma Virus (HPV) Vaccination}

The success of a vaccination strategy is ensured by universal immunization coverage, equal access to vaccination programs, and adequate training and knowledge among healthcare professionals. Although HPV vaccination rates among women are relatively high globally (118 million women aged 10-20), in several developing regions vaccination coverage as low as $1 \%$ is common, resulting in high rates of HPV-related cancer incidence ${ }^{2}$. Healthcare systems of some countries are either not willing or not able to fully cover vaccination cost and this is considered an important limitation in vaccination program effectiveness.

\section{Types of HPV Vaccines}

The following HPV vaccines have been licensed and approved ${ }^{2,4}$ :

- Bivalent (HPV2, Cervarix); Protection from HPV types 16,18

- Quadrivalent (HPV4, Gardasil4); Protection from HPV types 6, 11, 16, 18

- Nonavalent (HPV9, Gardasil 9); Protection from HPV types 6, 11, 16, 18, 31, 33, 45, 52, 58

The two types of vaccines available in Greece are the HPV2 and HPV9 vaccines.

\section{Protection Mechanism, Immunogenicity, and Efficacy of HPV Vaccines}

The key component of HPV vaccines is the capsid protein L1, which self-assembles into virus-like particles (VLPs). The production of the L1 protein is based on recombinant DNA technology ${ }^{2}$. The protection mechanism of HPV vaccines is demonstrated through the detection of neutralizing antibodies in genital mucosa and secretions after vaccination ${ }^{5}$. Serum antibody titers after vaccination have been shown to be higher than those occurring after natural infection ${ }^{2}$. Thus, HPV vaccines present excellent immunogenicity ${ }^{6}$ and long-lasting immunity ${ }^{7}$. International organizations, such as World Health Organization (WHO), European Medicines Agency (EMA) and Centers for Disease Control and Prevention (CDC), have proven and accepted the safety of HPV vaccines ${ }^{8}$, which have efficacy of almost $100 \%$ in terms of preventing cancerous and precancerous lesions ${ }^{2}$.

\section{Most Common Adverse Effects}

Reported adverse effects of HPV vaccines include fever, dizziness, nausea, syncope, headache, vomiting, diarrhea, and injection site reactions such as pain, redness, and swelling 8 .

\section{Contraindications}

Reasons for exclusion of HPV vaccination are presented in Table 1. 
Table 1. HPV vaccination exclusion criteria.

\section{HPV VACCINATION IS EXCLUDED IN CASE OF}

Hypersensitivity or Allergy to vaccine components

Severe allergic reaction to any vaccine component after first

dose

Severe infection or illnesses

DO NOT EXCLUDE HPV VACCINATION IN CASE OF

Concomitant administration with other vaccines

Lactation

Abnormal Pap test result

Condylomata or HPV infection

\section{Reasons for Non-Vaccination}

Inability to pay vaccination fees, lack of knowledge, inadequate or incorrect information from healthcare professionals, concerns regarding possible adverse effects, fear of injections, religious or cultural beliefs, and fear of being stigmatized are among the main reasons for non-vaccination. Greek mothers typically consider themselves to be well informed about HPV vaccination; yet concerns regarding possible adverse effects continue to be a basic obstacle to vaccination among Greek women.

\section{HPV Vaccine Schedule and Dosing}

Vaccine schedule and dosing both internationally and in Greece are presented in Tables 2 and 3 respectively.

In terms of protection from CIN2+ and CIN3+ lesions, vaccination after the age of 14 , known as "catch-up vaccination," has been shown to be beneficial for females aged 14-20 years, but not for those aged 21-26 years ${ }^{10,11}$. Clinical studies aim to define the number of vaccine doses required to guarantee and maintain immunity ${ }^{12,13}$

\section{Role of HPV9 Vaccine in People Completely or Partially Vaccinated with HPV2 or HPV4 Vaccines}

People who have completed HPV2 or HPV4 vaccination are immune to HPV types 16 and 18. Although not officially recommended, additional administration of the HPV9 vaccine may offer further benefits due to its wider coverage of HPV types; this would not, however, ensure equal immunity and protection from the other HPV types. In a recently updated committee opinion, the American College of Obstetricians and Gynecologists (ACOG) stated that HPV9 vaccination should not be routinely recommended for people who have completed either HPV2 or HPV4 vaccination ${ }^{14}$.

Regarding people who have only been partially vaccinated, the age at which they received their first vaccine dose, the total number of doses received, and the interval between doses should be taken into consideration. European recommendations suggest the continuation of doses based on the initial immunization schedule ${ }^{15}$, while in the US, any combination of doses is deemed acceptable as long as protection against types 16 and 18 is provided ${ }^{14}$.

\section{HPV Vaccination in different population groups \\ Appropriate Age for Commencement of Vaccination}

It is generally suggested that HPV vaccination should be initiated before the onset of sexual activ-

Table 2. HPV vaccine schedule and dosing.

$\begin{array}{lll}\text { TARGET GROUP } & \text { REGIMEN } & \begin{array}{l}\text { SCHEDULE } \\ \text { (INTERVALS) }\end{array} \\ <15 \text { years } & \text { Two doses } & (0,6)^{*} \\ >15 \text { years } & \text { Three doses } & (0,1-2,6) \\ \text { High risk population, } & \text { Three doses } & (0,1-2,6) \\ \text { 11-26 years } & & \end{array}$

*If the interval is shorter than five months, a third dose at least three months later is recommended

Table 3. Target groups for HPV vaccination in Greece.

9 9-12 years, catch-up vaccination up to 18 years old

$\uparrow$, ơ 11-26 years in case of immunosuppression and immunosuppressive drugs, HIV infection, cancer, transplantation, and autoimmune diseases

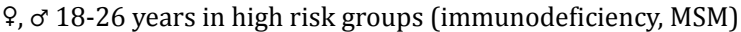


ity ${ }^{9,16}$, that is, before probable exposure to the virus. The younger the age at which vaccination commences, the stronger the response of the immune system. The WHO identifies girls aged 9-14 years as a target group, while the vaccination of older girls and women is suggested, depending on the goals of each vaccination program and on cost-effectiveness ${ }^{17}$. Meanwhile, the American Cancer Society (ACS) suggests that HPV vaccination is offered to boys and girls aged $9-12^{18}$. For children with a known history of sexual abuse, HPV vaccination should start as soon as possible, preferably at the age of 9 years ${ }^{14}$. HPV vaccination in women over the age of 25 has been shown to be safe and effective and to achieve sufficient immunogenicity ${ }^{19}$. Several countries recommend HPV vaccination for women up to 45 years old ${ }^{2,4}$.

\section{Recommendations for Pregnant and Breastfeeding Women}

During pregnancy, HPV vaccination should be postponed until the pregnancy's completion, although no correlations between HPV vaccination and adverse effects on pregnancy have been reported ${ }^{16}$. Vaccination may take place for women aged 26 years or younger who are breastfeeding and have not been previously vaccinated ${ }^{14}$.

\section{Gender-Neutral Vaccination}

Gender-neutral HPV vaccination has been included in the national immunization programs of several countries ${ }^{10}$. Recommendations, especially those regarding catch-up vaccination, are based on biological sex and not on gender identity; therefore, there is a lack of gender identity - based data on vaccination coverage. Transgender people should follow the same HPV vaccination schedule that is recommended for population up to 26 years old ${ }^{20}$.

\section{Recommendations for biologically male persons}

HPV vaccination for people whose birth-assigned sex is male contributes on the one hand to the expansion of immunization coverage and herd immunity ${ }^{10,13}$ and on the other hand to the prevention of penile and head and neck cancer. More data and clinical trials are required in order to clarify its impact on anal and oropharyngeal cancer prevention ${ }^{2}$. The availability of HPV vaccines and their costs affect vaccination among this population. The US Food and Drug Administration (FDA) has approved the use of HPV4 and HPV9 vaccines in birth-assigned males before the onset of sexual activity as a measure to prevent anal and genital HPV infections. Men who have sex with men (MSM) could also benefit from HPV4 vaccination, as it would reduce the risk of condylomata and intraepithelial dysplasia ${ }^{21}$.

\section{Vaccination of Sex Workers}

Despite the lack of specific data, sex workers stand to benefit from HPV vaccination, since they belong to a high-risk group for both HPV exposure and infection, and non-vaccination is common among them. Vaccination also mitigates the risk of transmission to their sexual partners ${ }^{11}$.

\section{Recommendations for People Already Exposed to HPV}

Vaccination of women already exposed to the virus is safe and strong immune responses can be achieved ${ }^{5,11}$, reducing the risks of transmission to their sexual partners, self-inoculation, and disease recurrence ${ }^{5}$. Various studies suggest that adjuvant administration of HPV preventive vaccines after treatment for CIN2+ lesions can help prevent recurrence or relapse of the lesions $s^{4,5,11,16,19}$. The therapeutic effect of HPV4 vaccine in women with CIN1 lesions has been demonstrated in a randomized clinical trial $^{22}$, the results of which are also supported by cohort studies ${ }^{4}$.

\section{Vaccination of Healthcare Workers}

Both the American Society for Colposcopy and 
Cervical Pathology (ASCCP) and ACOG recommend that HPV vaccination be considered for healthcare workers who may have been exposed to the virus while treating HPV-related lesions ${ }^{23}$.

\section{Future goals}

\section{Therapeutic HPV Vaccines}

Cohort studies have shown therapeutic HPV vaccines to be safe and well tolerated, but clinical effects have yet to be reported ${ }^{3}$, and such vaccines have not yet been licensed ${ }^{2}$. Therapeutic HPV vaccination is based on the following two theoretical foundations. First, it depends on cell-mediated immunity and the interaction with infected cells and the lesion microenvironment. Second, it depends on T-cytotoxic lymphocytes that are produced against oncoproteins (such as the E6 and E7 oncoproteins, which target the p53 and pRb genes, respectively, making them ideal antigens and such as the E1 and E2 oncoproteins, which are necessary for HPV replication $)^{2,3}$. Different carriers regarding heterologous protein expression, including viruses (adenoviruses, Poxviruses), bacteria, plasmids, peptides, and naked genetic material, are being investigated. Current protocols are investigating checkpoint blockade therapy either in combination or as a monotherapy in UCC treatment. Administration of the anti-CD25 antibody, chemoimmunotherapy, and targeted immunotherapy are expected to enhance the effect of therapeutic HPV vaccines ${ }^{3}$. It is important to mention, that, currently, there are clinical trials regarding therapeutic HPV vaccination in phases $1 \mathrm{~b} / 2$ and $3^{24}$.

\section{HPV Vaccination Beyond Healthcare Centers}

HPV vaccination in schools and community centers combined with vaccination campaigns could boost and increase immunization coverage. However, ensuring the accessibility of the facilities, sufficiently low costs, and compliance with national vaccination program recommendations require organization, coordination, and constant communication.

\section{HPV-FASTER Protocol}

The HPV-FASTER protocol suggests widening the vaccination age range to 9-45 years regardless of HPV infection status and initiating HPV DNA screening in women aged $25-30$ years. A marked advantage of this protocol is the reduction in the number of screening visits, leading to greater compliance and reduced workloads for healthcare systems ${ }^{13}$.

\section{Uterine Cervical Cancer (UCC) Elimination}

UCC elimination could be achieved through new national goals, including vaccination coverage goals aiming for up to $90 \%$ among 15 -year-old girls, screening and highly accurate tests for $70 \%$ of all women, and treatment of $90 \%$ of precancerous and invasive lesions. In Australia, for example, UCC incidence in 2100 is projected to be 2.31 cases per 100,000 women, if the HPV9 vaccine is administered without screening tests, while a combination of vaccination and screening could reduce incidence to 0.57 cases per 100,000 women ${ }^{25}$.

\section{Secondary prevention}

\section{The Pap Test and Its Main Disadvantages}

The Pap test is a classic or liquid-based cytology test that identifies abnormal cells from the transitional zone of the cervix and the squamocolumnar junction, where dysplasia and cancer develop. Its widespread use as a screening method led to an exponential decrease in the incidence of cervical cancer worldwide. Nonetheless, data from Europe and North America show a relative stabilization in this decline from 1970 onwards ${ }^{26}$, while the disadvantages of the Pap test have become more evident.

Various meta-analyses have shown that the sensitivity and specificity of the Pap test vary. The test is subjective, and it is largely dependent on human 
factors and on the expertise of the gynecologist (in sample collection) and pathologist (in sample analysis). One systematic review reported that the specificity of the test ranged from $86-100 \%$, while the sensitivity ranged from $30 \%-87 \%$, leading to a high number of false negative tests ${ }^{27}$.

The Pap test is even less sensitive in terms of detecting adenocarcinoma and adenocarcinoma in $\mathrm{situ}^{28}$, whose incidences have increased in recent years, despite squamous carcinoma still being the commonest cancer type. This lower sensitivity is probably attributed to the fact that adenocarcinoma often presents with skip lesions, which are more difficult to detect during cervical examination.

Moreover, some women may undergo unnecessary colposcopy due to the Pap test. In a Canadian study, 60 women aged 20-29 were led to colposcopy, with 13 of them having part of their cervix removed due to the presence of abnormal cells detected by the Pap test. In 9 of these 13 cases, the study concluded that the procedure had been unnecessary, as the abnormal cells would never have developed into cancer ${ }^{29}$.

\section{HPV DNA Testing}

Given the indissoluble relationship between HPV and cervical cancer, HPV DNA testing was developed aiming to find a more effective screening method. The test identifies the DNA of the 14 most common high-risk HPV types in uterine cervical cells. The sampling procedure is similar to the one used in the Pap test.

The HPV DNA test offers multiple advantages, with its high sensitivity being one of the most important. This contributes to better lesion detection, lower morbidity, and lengthening of the periods between screening, which increases screening compliance and reduces costs ${ }^{30}$. Despite these advantages, the test presents a moderately lower specificity, resulting in more false positive results and in an increase in the number of colposcopy referrals ${ }^{31}$.
Selecting the right HPV DNA test is crucial. More than 200 tests are commercially available, but only five have been approved by the FDA, as shown in Table $4^{32}$.

Tests that can detect HPV mRNA are also available $^{33}$, thus being able to identify not only the presence of the virus but also its activity. The use of such tests as screening tools is under investigation.

\section{Screening options}

Available HPV screening options are presented in Table 5.

\section{The Pap Test Versus the HPV DNA Test}

Consistent evidence provided by various studies supports the use of the HPV DNA test as opposed to the Pap test, due to the former's higher sensitivity $^{31,34,35}$.

\section{Primary HPV DNA Test Versus Co-Testing}

Whether to choose primary HPV DNA test or cotesting (using the Pap test in addition to the HPV DNA test) represents the most common question

Table 4. FDA approved HPV DNA tests.

1) Digene HC2 No

2) Cervista $\quad \alpha$ )Cervista HPV HR: no $\beta)$ Cervista HPV 16/18: yes, types 16 and 18

3) Aptima $\quad \alpha$ ) Aptima HPV: no ß) Aptima HPV 16, 18/45: yes, types 16 (separately) and 18, 45 (together)

4) Cobas Yes, 16, 18, 12 or other

5) Onclarity Yes, $16,18,45,11$ or other

Table 5. HPV Screening options.

$\begin{array}{ll}\text { 1) Pap test } & \text { initial test with Pap test only } \\ \text { 2) reflex HPV testing } & \text { HPV DNA test only if Pap test is } \\ \text { (triage HPV testing) } & \text { positive } \\ \text { 3) co-testing } & \text { Pap test and HPV DNA test together } \\ \text { 4) primary HPV DNA test } & \text { initial test with HPV DNA test only } \\ \text { 5) reflex Pap test } & \begin{array}{l}\text { Pap test only if HPV DNA test is } \\ \text { positive }\end{array}\end{array}$


concerning cervical cancer screening, as these two testing methods are considered to be the most effective ones. Various studies have sought to answer this question. In a large study conducted in California, US, 1,208,710 women aged 30 and above underwent screening with co-testing every three years. The HPV DNA test was assumed to be superior to the Pap test. In comparison to the Pap test, the study found that the HPV DNA test identified more women with precancerous or cancerous lesions and was more likely to be positive in any cancer stage, except during the first 12 months. Co-testing, meanwhile, was found to lead to the early detection of a maximum of 5 cases per 1,000,000 women ${ }^{36}$. However, another study concluded that co-testing would not only lead to fewer cases of invasive CIN3+ UCC but would also be of greater economic value in the long term ${ }^{37}$.

\section{Screening recommendations in various countries' national guidelines}

Although there are minor differences between different countries' guidelines, they generally agree that primary Pap testing should be replaced with either primary HPV DNA test or co-testing. Guidelines of international organizations are summarized in Table 6.

\section{Screening participation rates}

Data from European countries, North America and Australia (i.e., countries with well-organized national screening programs and clear recommendations) indicate relatively low participation rates in cervical cancer screening. One 2018 study analyzed participation rates in cervical and breast cancer screening programs of 17 European countries during the years 2004-2014, and investigated the relationship between these participation rates and socioeconomic factors. The study reported low but relatively stable rates of participation in cervical cancer screening throughout the years, with higher participation rates associated with younger women (those aged less than 50 years) and with higher Gini index. The highest participation rates were observed in the following northern European countries: Finland (2004: 71.6\%; 2014: 70.6\%), Iceland (2004: 70\%; 2014: 70\%), Ireland (2004: 60.9\%; 2014: 77\%), and the United Kingdom (2004: 80.6\%; 2014: 77.5\%). The lowest participation rates were observed in the following southern and eastern European countries: Italy (2004: 37.7\%; 2014: 40.5\%) and Estonia (2004: 32\%; 2014:50\%). The study did not analyze screening rates in Greece due to the unavailability of the relevant data ${ }^{50}$.

In December 2019, exactly two years after the implementation of the renewed NCSP (National Cervical Screening Program), Australia published the first data on screening program participation rates. It has been noted, however, that these data are not comparable with data published in previous years due to the short time since the implementation of the renewed NCSP. In 2018, under the new program, a participation rate of 54\% among women aged 25-74 years has been estimated, similar to rates observed under the previous NCSP ${ }^{51}$.

\section{The role of self-sampling}

Self-sampling, in which women collect the sample for the HPV DNA test from themselves, has arisen as a promising solution to the problem of insufficient participation in screening programs. Multiple studies have shown that self-sampling is both acceptable to women and effective. A 2019 meta-analysis demonstrated that women who were given the option of self-sampling were twice as likely to participate in screening, and there was no important difference in the follow-up of these women, compared to those who did not use self-sampling ${ }^{52}$. The contribution of self-sampling may be especially crucial in vulnerable populations ${ }^{53}$.

Self-sampling has been included in the guidelines of countries such as Denmark, while more and more 
Table 6. International UCC Screening Guidelines.

\begin{tabular}{|c|c|c|}
\hline COUNTRY & $\begin{array}{l}\text { SCREENING } \\
\text { AGES }\end{array}$ & $\begin{array}{l}\text { ORGANIZATIONS*; DETAILED } \\
\text { GUIDELINES \& RECOMMENDATIONS }\end{array}$ \\
\hline $\begin{array}{l}\text { United States } \\
\text { of America }\end{array}$ & $21-65$ years old ${ }^{38}$ & $\begin{array}{l}\text { ASCCP, SGO, ACOG } \\
\text { Ages 21-29: Primary Pap test every three } \\
\text { years }^{39,40} \text {. }\end{array}$ \\
\hline & & $\begin{array}{l}\text { After age 25: Primary HPV DNA test every } \\
\text { three years }{ }^{40} \text {. } \\
\text { ASCCP, SGO, ACOG, ACS } \\
\text { Ages } 30 \text { and above: Co-testing every five } \\
\text { years or primary HPV DNA test every five } \\
\text { years. If primary Pap test is chosen, it is } \\
\text { recommended every three years }{ }^{39,41} \text {. }\end{array}$ \\
\hline
\end{tabular}

Canada

$\begin{array}{ll}\text { United } & \text { 24.5-64 years } \\ \text { Kingdom } & \text { old }\end{array}$
or $70^{44}$
21 or 25 until 65 Pap test every two or three years.

\section{CADTH, HTERP}

Recommend implementing primary HPV DNA test as the main screening method ${ }^{45}$.

Ages 24.5-49: HPV DNA test every three years.

Ages 50-64: Five-year intervals between screening tests ${ }^{48}$.

\section{SUPPLEMENTARY COMMENTS}

In the 21-29 years age group, the Pap test is preferred as young women have higher chances of HPV infection, but in the majority of these cases, the infection will be temporary and self-limited, with regression of the lesions. A positive HPV DNA test would lead to an unnecessary colposcopy ${ }^{28,42}$. ASCCP, 2019, concerning steps after screening: - When colposcopy, treatment or surveillance are being considered, evaluation of patient's risk for CIN3+ lesions is recommended and not of the test results.

- In case of minor abnormalities with a low risk of CIN3+ lesions, HPV DNA test or co-testing could be performed in order to delay colposcopy for a year.

- Individuals with a positive HPV DNA test should undergo a reflex test, such as a reflex Pap test, using the same specimen ${ }^{43}$.

ACS, 2020, updated guidelines: primary HPV testing for average-risk women aged 25-65. Strong recommendations for "phasing out cytology-based screening options in the near future"

CCS, concerning the HPV DNA test:

- Used as an additional tool to the Pap test for women aged over 30 years.

- Used in the follow-up of women with any kind of abnormality found in the Pap test, for instance ASCUS cells ${ }^{46}$.

CADTH report, 2019:

The effectiveness of the HPV DNA test in detecting precancerous lesions was prominent. It was not as effective in detecting cases of HPV infection without cancer, and more colposcopy referrals were noted. However, it is concluded that primary HPV DNA testing offers greater sensitivity, longer intervals between screenings, later commencement of screening, and cost reduction ${ }^{47}$. HTERP, 2019:

No specific test recommendations. If the HPV DNA test is chosen, five-year intervals for women aged 25-69 years are appropriate. Primary HPV DNA testing is recommended as the preferred screening method for the population ${ }^{44}$. 
Table 6. International UCC Screening Guidelines (continued).

$\begin{array}{lll}\text { COUNTRY } & \text { SCREENING } & \text { ORGANIZATIONS*; DETAILED } \\ \text { Australia } & \text { 25-74 years old } & \text { NCSP } \\ & \text { Ages 25-74: HPV DNA test every five years; } \\ & \text { this is followed by a reflex Pap test only after } \\ & \text { a positive HPV DNA test result. } \\ & \text { Previously up to 2017: Pap test every two } \\ & \text { years for women aged 20-69 years old }{ }^{49} . \\ & \text { Hellenic Society of Obstetrics and } \\ & \text { Gynecology } \\ & \text { Recently revised national guidelines (July } \\ & \text { 2021): } \\ & \text { Ages 21-30: Pap test every 3 years } \\ & \text { Ages 30-65: co-testing every 3 years } \\ & \text { It is important, however, to mention that } \\ & \text { there are still incidents of no compliance } \\ & \text { with international and national guidelines. } \\ & \text { In many cases, the primary Pap test is still } \\ & \text { being used, mostly annually, with unclear } \\ & \text { ages for commencement and termination of } \\ \text { screening. }\end{array}$

*Organizational abbreviations: American Society for Colposcopy and Cervical Pathology (ASCCP), Society of Gynecologic Oncology (SGO), American College of Obstetricians and Gynecologists (ACOG), American Cancer Society (ACS), Canadian Agency for Drugs and Technologies in Health (CADTH), Health Technology Expert Review Panel (HTERP), Canadian Cancer Society (CCS), National Cervical Screening Program (NCSP).

countries, including the United Kingdom, have piloted similar self-sampling programs.

\section{Women already vaccinated against HPV}

To date, no special recommendations exist for women already vaccinated against $\mathrm{HPV}^{39}$. There are questions concerning the number of tests women who completed HPV9 vaccination should undergo. One study demonstrated that HPV DNA testing every 10 years could be sufficient for women fully vaccinated with HPV9 at the age of 12 . Analytically, if screening begins at 35 and is followed by further tests at ages 45,55 , and 65 (four tests in total), 98\% protection against cervical cancer is achieved, while if an additional initial test is done at the age of 30 (i.e., five tests in total at the ages of $30,35,45,55,65$ ), protection of up to $99 \%$ is achieved ${ }^{54}$.

\section{SUPPLEMENTARY COMMENTS}

(SGO), 
sively extending screening intervals. Furthermore, self-sampling in secondary prevention of UCC has gained special importance in this context, and therefore its use should be promoted widely during the COVID-19 pandemic ${ }^{55}$.

\section{Conclusion}

Both primary and secondary preventive measures are essential for achieving not only control but also elimination of UCC. The combination of HPV vaccination and screening tools, the constantly expanding research and clinical field, and the ongoing and thorough education of healthcare professionals, general population, and specific target groups have made elimination of the disease an achievable goal. This is imprinted on HPV recommendations and guidelines of various countries. Greek healthcare professionals are encouraged to adopt a similar approach and comply with the recently updated national guidelines.

\section{Discussion}

The benefits arising from well-organized national preventive programs of countries such as Australia and Canada are evident. We strongly believe that Greece's current challenge is to follow in the footsteps of those countries by promoting the newly developed national guidelines and incorporating them into everyday clinical practice. If this challenge is grasped, Greece could join the league of countries dedicated to eliminating UCC.

\section{References}

1. Bruni L, Albero G, Serrano B, Mena M, Gómez D, Muñoz J, et al. Human Papillomavirus and Related Diseases in the World. Summary Report. ICO/ IARC Information Centre on HPV and Cancer (HPV Information Centre); 17 June 2019.

2. Garbuglia AR, Lapa D, Sias C, Capobianchi MR, Del Porto P. The Use of Both Therapeutic and Prophy- lactic Vaccines in the Therapy of Papillomavirus Disease. Front Immunol. 2020;11:188.

3. Hancock G, Hellner K, Dorrell L. Therapeutic HPV vaccines. Best Pract Res Clin Obstet Gynaecol. 2018;47:59-72.

4. Ghelardi A, Parazzini F, Martella F, Pieralli A, Bay P, Tonetti A, et al. SPERANZA project: HPV vaccination after treatment for CIN2. Gynecol Oncol. 2018;151(2):229-34.

5. Vorsters A, Van Damme P, Bosch FX. HPV vaccination: Are we overlooking additional opportunities to control HPV infection and transmission? Int J Infect Dis. 2019;88:110-2.

6. FDA. FDA approves expanded use of Gardasil 9 to include individuals 27 through 45 years old October 05, 2018 [Available from: https://www.fda. gov/news-events/press-announcements/fda-approves-expanded-use-gardasil-9-include-individuals-27-through-45-years-old.

7. Romanowski B, de Borba PC, Naud PS, Roteli-Martins CM, De Carvalho NS, Teixeira JC, et al. Sustained efficacy and immunogenicity of the human papillomavirus (HPV)-16/18 AS04-adjuvanted vaccine: analysis of a randomised placebo-controlled trial up to 6.4 years. Lancet (London, England). 2009;374(9706):1975-85.

8. Kuehn B. Studies Support HPV Safety. JAMA. 2020;323(4):302.

9. Sotiriadis A, Dagklis T, Siamanta V, Chatzigeorgiou $\mathrm{K}$, Agorastos T. Increasing fear of adverse effects drops intention to vaccinate after the introduction of prophylactic HPV vaccine. Archives of gynecology and obstetrics. 2012;285(6):1719-24.

10. Drolet M, Bénard É, Pérez N, Brisson M, Ali H, Boily $\mathrm{M}-\mathrm{C}$, et al. Population-level impact and herd effects following the introduction of human papillomavirus vaccination programmes: updated systematic review and meta-analysis. The Lancet. 2019;394(10197):497-509.

11. Schim van der Loeff MF, Vorsters A, Marra E, 
Van Damme P, Hogewoning A. Should female sex workers be offered HPV vaccination? Hum Vaccin Immunother. 2019;15(7-8):1544-8.

12. Sankaranarayanan R, Prabhu PR, Pawlita M, Gheit $\mathrm{T}$, Bhatla N, Muwonge R, et al. Immunogenicity and HPV infection after one, two, and three doses of quadrivalent HPV vaccine in girls in India: a multicentre prospective cohort study. The Lancet Oncology. 2016;17(1):67-77.

13. Bosch FX, Robles C. HPV-FASTER: Combined strategies of HPV vaccination and HPV screening towards a one visit for cervical cancer preventive campaigns. Salud Publica Mex. 2018;60(6):612-6.

14. Human Papillomavirus Vaccination: ACOG Committee Opinion, Number 809. Obstet Gynecol. 2020;136(2):e15-e21.

15. EMA. Gardasil 9. European public assessment report. EMA; 2015.

16. Arbyn M, Xu L, Simoens C, Martin-Hirsch PPL. Prophylactic vaccination against human papillomaviruses to prevent cervical cancer and its precursors. Cochrane Database of Systematic Reviews. 2018(5).

17. WHO. Human papillomavirus vaccines: WHO position paper, May 2017. Releve epidemiologique hebdomadaire. 2017;92(19):241-68.

18. McDowell S. ACS Updates HPV Vaccination Recommendations to Start at Age 92020 [Available from: https://www.cancer.org/latest-news/acsupdates-hpv-vaccination-recommendations-tostart-at-age-9.html.

19. Wheeler CM, Skinner SR, Del Rosario-Raymundo MR, Garland SM, Chatterjee A, Lazcano-Ponce E, et al. Efficacy, safety, and immunogenicity of the human papillomavirus 16/18 AS04-adjuvanted vaccine in women older than 25 years: 7 -year follow-up of the phase 3, double-blind, randomised controlled VIVIANE study. The Lancet Infectious Diseases. 2016;16(10):1154-68.

20. AAFP. Human Papillomavirus Vaccine (HPV)
[Available from: https://www.aafp.org/patientcare/public-health/immunizations/disease-population/hpv.html.

21. Winer RL, Lin J, Querec TD, Unger ER, Stern JE, Rudd JM, et al. Effectiveness of Human Papillomavirus (HPV) Vaccination Against Penile HPV Infection in Men Who Have Sex With Men and Transgender Women. The Journal of Infectious Diseases. 2021.

22. Karimi-Zarchi M, Allahqoli L, Nehmati A, Kashi AM, Taghipour-Zahir S, Alkatout I. Can the prophylactic quadrivalent HPV vaccine be used as a therapeutic agent in women with CIN? A randomized trial. BMC public health. 2020;20(1):274.

23. Harrison R, Huh W. Occupational Exposure to $\mathrm{Hu}-$ man Papillomavirus and Vaccination for Health Care Workers. Obstet Gynecol. 2020;136(4): 663-5.

24. HPV Vaccines 2021 [updated September 19, 2021. Available from: https://www.precisionvaccinations.com/vaccines/hpv-vaccines.

25. Hall MT, Simms KT, Lew JB, Smith MA, Brotherton JM, Saville M, et al. The projected timeframe until cervical cancer elimination in Australia: a modelling study. Lancet Public Health. 2019;4(1):e19-e27.

26. WHO. Cancer Fact Sheets: Cervical Cancer 2016 [Available from: https://gco.iarc.fr/today/data/ pdf/fact-sheets/cancers/cancer-fact-sheets- 16 . pdf.

27. Nanda K, McCrory DC, Myers ER, Bastian LA, Hasselblad V, Hickey JD, et al. Accuracy of the Papanicolaou test in screening for and follow-up of cervical cytologic abnormalities: a systematic review. Annals of internal medicine. 2000;132(10):810-9.

28. Castle PE, Katki HA. Benefits and risks of HPV testing in cervical cancer screening. The Lancet Oncology. 2010;11(3):214-5.

29. Québec Gd. Advantages and Disadvantages of Cervical Cytology Screening (Pap Test). July 4, 2017. 
30. Origoni M, Cristoforoni P, Costa S, Mariani L, Scirpa P, Lorincz A, et al. HPV-DNA testing for cervical cancer precursors: from evidence to clinical practice. ecancermedicalscience. 2012;6.

31. Koliopoulos G, Nyaga VN, Santesso N, Bryant A, Martin-Hirsch PP, Mustafa RA, et al. Cytology versus HPV testing for cervical cancer screening in the general population. The Cochrane Database of Systematic Reviews. 2017;2017(8).

32. FDA. New Approaches in the Evaluation for HighRisk Human Papillomavirus Nucleic Acid Detection Devices 2019 [Available from: https://www. fda.gov/media/122799/download.

33. Derbie A, Mekonnen D, Woldeamanuel Y, Van Ostade X, Abebe T. HPV E6/E7 mRNA test for the detection of high grade cervical intraepithelial neoplasia (CIN2+): a systematic review. Infectious Agents and Cancer. 2020;15(1):9.

34. Ogilvie GS, van Niekerk D, Krajden M, Smith LW, Cook D, Gondara L, et al. Effect of Screening With Primary Cervical HPV Testing vs Cytology Testing on High-grade Cervical Intraepithelial Neoplasia at 48 Months: The HPV FOCAL Randomized Clinical Trial. JAMA. 2018;320(1):43-52.

35. NSS. New HPV test more effective for identifying the risk of cervical cancer 2020 [updated 8 October 2020. Available from: https://nhsnss.org/ blog-news/articles/new-hpv-test-more-effective-for-identifying-the-risk-of-cervical-cancer/.

36. Schiffman M, Kinney WK, Cheung LC, Gage JC, Fetterman B, Poitras NE, et al. Relative Performance of HPV and Cytology Components of Cotesting in Cervical Screening. JNCI: Journal of the National Cancer Institute. 2018;110(5):501-8.

37. Felix JC, Lacey MJ, Miller JD, Lenhart GM, Spitzer M, Kulkarni R. The Clinical and Economic Benefits of Co-Testing Versus Primary HPV Testing for Cervical Cancer Screening: A Modeling Analysis. Journal of women's health (2002). 2016;25(6):606-16.
38. ACOG. Updated Cervical Cancer Screening Guidelines 409 12th Street SW, Washington, DC 20024-2188: American College of Obstetricians and Gynecologists; 2021 [Available from: https://www.acog.org/clinical/clinical-guidance/practice-advisory/articles/2021/04/ updated-cervical-cancer-screening-guidelines.

39. Saslow D, Solomon D, Lawson HW, Killackey M, Kulasingam S, Cain J, et al. American Cancer Society, American Society for Colposcopy and Cervical Pathology, and American Society for Clinical Pathology Screening Guidelines for the Prevention and Early Detection of Cervical Cancer. CA: a cancer journal for clinicians. 2012;62(3):147-72.

40. Huh WK, Ault KA, Chelmow D, Davey DD, Goulart RA, Garcia FAR, et al. Use of primary high-risk human papillomavirus testing for cervical cancer screening: interim clinical guidance. Gynecologic Oncology. 2015;136(2):178-82.

41. Huh WK, Ault KA, Chelmow D, Davey DD, Goulart RA, Garcia FA, et al. Use of primary high-risk human papillomavirus testing for cervical cancer screening: interim clinical guidance. Journal of Lower Genital Tract Disease. 2015;19(2):91-6.

42. Ronco G, Giorgi-Rossi P, Carozzi F, Confortini M, Dalla Palma P, Del Mistro A, et al. Efficacy of human papillomavirus testing for the detection of invasive cervical cancers and cervical intraepithelial neoplasia: a randomised controlled trial. The Lancet Oncology. 2010;11(3):249-57.

43. Perkins RB, Guido RS, Castle PE, Chelmow D, Einstein MH, Garcia F, et al. 2019 ASCCP Risk-Based Management Consensus Guidelines for Abnormal Cervical Cancer Screening Tests and Cancer Precursors. Journal of Lower Genital Tract Disease. 2020;24(2):102-31.

44. CADTH. HPV Testing for Primary Cervical Cancer Screening 2019 [updated July 8 2019. Available from: https://www.cadth.ca/ hpv-testing-primary-cervical-cancer-screening. 
45. Smith L, Niekerk Dv, Coldman A, Krajden M, Franco EL, Ogilvie G. Recommendations for Implementing Human Papillomavirus-Based Cervical Cancer Screening: Lessons Learned from the HPV FOCAL Trial. Journal of Obstetrics and Gynaecology Canada. 2016;38(8):723-6.

46. CCS. Human papillomavirus (HPV) test - Canadian Cancer Society [Available from: https:// www.cancer.ca/en/cancer-information/diagnosis-and-treatment/tests-and-procedures/ hpv-test/?region=on.

47. HPV Testing for Primary Cervical Cancer Screening 2016 [updated 2016-12-13T13:05:1205:00. Available from: https://www.cadth.ca/ hpv-testing-primary-cervical-cancer-screening.

48. Cervical screening: implementation guide for primary HPV screening Updated 2019 [Available from: https://www.gov.uk/government/publications/cervical-screening-primary-hpv-screeningimplementation/cervical-screening-implementation-guide-for-primary-hpv-screening.

49. National Cervical Screening Program monitoring report 2019, 2019 [Available from: https://www. aihw.gov.au/reports/cancer-screening/nationalcervical-screening-monitoring-2019/contents/ table-of-contents.

50. Gianino MM, Lenzi J, Bonaudo M, Fantini MP, Siliquini R, Ricciardi W, et al. Organized screening programmes for breast and cervical cancer in $17 \mathrm{EU}$ countries: trajectories of attendance rates. BMC public health. 2018;18(1):1-13.
51. National cancer screening programs participation data, National Cervical Screening Program [Available from: https://www.aihw.gov. $\mathrm{au} /$ reports/cancer-screening/national-cancerscreening-programs-participation/contents/ national-cervical-screening-program.

52. Yeh PT, Kennedy CE, de Vuyst H, Narasimhan M. Self-sampling for human papillomavirus (HPV) testing: a systematic review and meta-analysis. BMJ global health. 2019;4(3):e001351.

53. Nodjikouambaye ZA, Adawaye C, Bouassa R-SM, Sadjoli D, Bélec L. A systematic review of self-sampling for HPV testing in Africa. International Journal of Gynecology \& Obstetrics. 2020;149(2):123-9.

54. Castle PE. When Less is More. JNCI: Journal of the National Cancer Institute. 2017;109(2).

55. Ciavattini A, Delli Carpini G, Giannella L, Arbyn M, Kyrgiou M, Joura EA, et al. European Federation for Colposcopy (EFC) and European Society of Gynaecological Oncology (ESGO) joint considerations about human papillomavirus (HPV) vaccination, screening programs, colposcopy, and surgery during and after the COVID-19 pandemic. International journal of gynecological cancer: official journal of the International Gynecological Cancer Society. 2020;30(8):1097-100.

Received 02-09-21

Revised 08-09-21

Accepted 14-09-21 